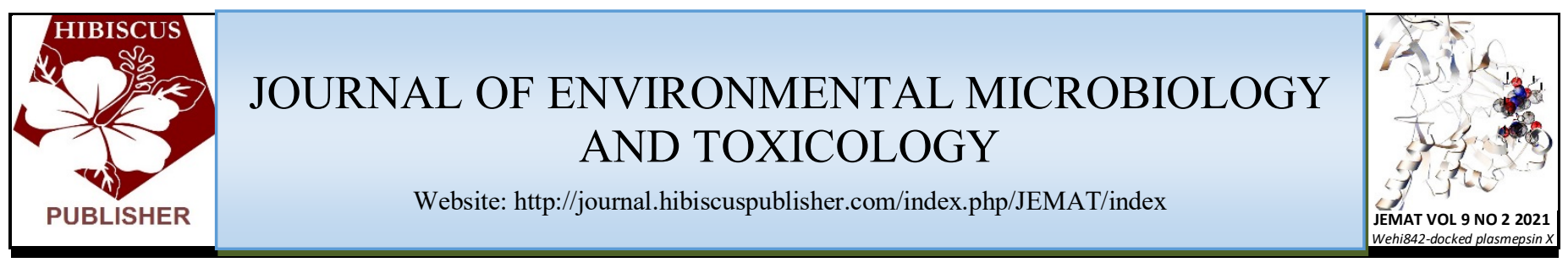

\title{
Effects of Nigerian Walnut (Juglan nigra) Lectin on Haematological Parameters and Lethal Dose (LD50) on Swiss Wistar
}

\author{
Lawrence Alexander ${ }^{1}$, Uchejeso Obeta ${ }^{2}$, Michael Okungbowa ${ }^{3}$, Isaac Emeje ${ }^{4}$, Jonathan Sabulu ${ }^{5}$, Gumta \\ Matthew $^{6}$, Priscilla Agbalaka ${ }^{7}$ and Ezeanyagu Oluchi ${ }^{7}$ \\ ${ }^{1}$ Department of Haematology. Federal Medical Centre, Lokoja, Nigeria. \\ ${ }^{2}$ Department of Medical Laboratory Management, Federal School of Medical Laboratory Science, Jos, Nigeria \\ ${ }^{3}$ Department of Haematology. College of Basic Medicine, University of Benin, Benin, Nigeria. \\ ${ }^{4}$ Department of Chemical Pathology, Federal Medical Centre, Lokoja, Nigeria. \\ ${ }^{5}$ Department of Obstetrics and Gynaecology, Federal Teaching Hospital Gombe, Nigeria. \\ ${ }^{6}$ Department of Family Medicine, OLA Hospital Jos, Nigeria. \\ ${ }^{7}$ Department of Parasitology, Federal School of Medical Laboratory Science, Jos, Nigeria \\ *Corresponding author: \\ Uchejeso Obeta, \\ Department of Medical Laboratory Management, \\ Federal School of Medical Laboratory Science, \\ Jos, \\ Nigeria. \\ Email:uchejesoobeta@gmail.com
}

\section{HISTORY}

Received: $24^{\text {th }}$ Oct 2021

Received in revised form: $15^{\text {th }}$ Nov 2021 Accepted: $18^{\text {th }}$ Dec 2021

\section{KEYWORDS}

Juglan nigra

Nigerian walnut

Lectin

Haematological parameters

$\mathrm{LD}_{50}$

\begin{abstract}
This study was designed to investigate the effects of Juglan nigra lectin on haematological parameters and lethal dose of rats. An authenticated Juglan nigra (UBHP401) collected from Lokoja was used to extract lectin and treated on Swiss Wistar rats $(n=35)$ and $(n=17)$ with weights from $75-129 \mathrm{~g}$ for haematological parameters and LD50 respectively. The Wistar rats were divided into five equal groups labeled A, B, C, D, and E. Lectin concentrations were prepared and administered at stipulated days. Group A served as control, group B received 30\%, C received $50 \%$, D received $70 \%$ and group E received $90 \%$ of lectin intraperitoneally. Samples (Baseline$\mathrm{BL}$, First Harvests-FH and Second Harvest-SH) were collected from all the groups and analyzed for the following haematological parameters: white blood count (WBC), Red Blood count (RBC), Haemoglobin (HB), packed cell volume (PCV), platelet count, neutrophil, lymphocyte, monocytes, eosinophil and basophil. The data were analysed using two-way analysis of variance (ANOVA) in graph pad prism version 5.03. The Eosinophil count and white blood cell count were significantly increased $\mathrm{P}<0.005$ and 0.05 , whereas the $\mathrm{HB}, \mathrm{PCV}$ and $\mathrm{RBC}$ showed significant different $\mathrm{P}<0.05$ based on the day of exposure of the animal to the lectin, the platelet count was significantly increased on the basis of days of exposure of $\mathrm{P}<0.05$, Eosinophil significantly increased too. Juglan nigra, (Nigerian walnut) Lectin is nontoxic as noted from $\mathrm{LD}_{50}$ result. Nigerian walnut lectin has a positive effect in haematopoietic activity of Swiss Wistar rats.
\end{abstract}

\section{INTRODUCTION}

Juglan nigra, a Nigerian native stone fruit with a solitary secretion, is farmed for its nut, which can be eaten raw or fried as a snack [1]. African Walnut is scientifically known as Tetracarpidium conophoram. To name a few, there's several nut families, including Euphorbiaceae (containing Tetracarpidium conophoram) and Olacaceae which also includes Coula edults. The crude protein level of walnuts (Juglan nigra) is $25 \%$ and the fat content is $60 \%$. Other minerals present in walnut seeds that are useful to the body include manganese and potassium, phosphorus, zinc, and magnesium. The diary contents of Juglan nigra seed have a noteworthy effect on blood components. Longterm nutritional status can be evaluated using nutritional status in blood and body fluids. It is widely known that haematological values can be used to assess an animal's overall health as well as to diagnose or forecast the fate of numerous animal disorders [3]

Juglan nigra possesses lectinic characteristics and activity, according to reports. The effects of this lectin on its activities, on the other hand, were scarce in the extant literatures [4]. As a result, this research will contribute significantly to the vital or crucial action of this lectin. Determining the hematopoietic activities of various metabolic or biochemical isolates, such as 
lectin, is vital for health because understanding if they are causative agents or suppressors of hematopoietic cell lines will be of tremendous therapeutic and medicinal academic research use. As a result, commencing on this study project becomes justified. Dietary lectins are protein antigens that bind to glycoproteins or glycolipids on the surface of erythrocytes or lymphocytes. They act as allergens as well as haemagglutinins. They are found in plants and animals and are present in modest amounts in 30\% of American food, with a higher concentration in a whole grains diet [5]. Purified lectins are used to determine blood type (ABO). Castor bean lectin is highly poisonous and can kill if even a small amount is consumed. Lectin from kidney beans has been linked to a food poisoning event with no known pathogen [6]. Lectins from soybean, peas, faba bean lentile, and sainfoin have conserved amino acids implicated in metal binding. The other legume lectin substitutes phenlalanine for the tyrosine residue at position 12 of concavalin A. Essentially, several genotypic lectins have been utilised in laboratories to sort blood $[4,7]$.

In healthy individuals, several plant lectins that bind specifically to distinct carbohydrate determinants of glycoprotein promote platelet aggregation. It has been demonstrated that phytohaemagglutinin (PHA) and wheat germ agglutinin (MGA) cause more significant platelet aggregation than concanavalin A. (ConA). LCA (Lens culinans agglutinin) has a minor aggregation activity. It was suggested that carbohydrate determinants of platelet glycoproteins serve various roles [8]. The purpose of this study is to look into the hematopoietic activities or potentials of African Juglan nut lectin in Albino rats, with the specific goals of analyzing the impacts of Juglan nigra nut lectin on the blood parameters and $\mathrm{LD}_{50}$ of Wistar rats.

\section{MATERIALS AND METHODS}

\section{Collection of Materials}

Walnut (Juglan, Nigra) were collected from its natural habitat in Lokoja and Ondo States from May to June, 2018 and it was confirmed in Botany Department University of Benin with herbarium reference number UBHP401. The research was carried out in Animal house or animal husbandry of Federal University Lokoja.

\section{Preparation of Walnut Lectin}

The method was adapted from Vijaya et al [9]. Using a homogenizer, the seeds were thoroughly pulverized. The oily component was removed, uniformly homogenized with petroleum ether (40-60 mL), and maintained at 2-4 hours with intermittent stirring. It was filtered with a fresh filter cloth. For 10 minutes, the filtrate was centrifuged at $800 \mathrm{rpm}$. The filtrate and centrifugation residues were collected and air dried at room temperature.

The air-dried powder of walnut seed was then combined uniformLy with $1 \%$ acetic acid and left overnight before being filtered via cloth. The filtrate was centrifuged at $9000 \mathrm{rpm}$ for 15 minutes. The clear solution supernatant was collected and adjusted to $100 \%$ saturation by adding solid ammonium sulphate while stirring continuously. Centrifugation was used to remove the lectin from the solution, which was then diluted in a small amount of deionized water and dialyzed against distilled water for 24 hours at 40 degrees Celsius with many changes. The crude lectin was purified on a column of chromatography lined with sulphadex G-72 for 24 hours at 40 degrees Celsius using $50 \mathrm{~mm}$ borate buffer, $\mathrm{PH}$ 8.4. A fraction collector was used to collect $3 \mathrm{~mL}$ fractions of the eluate. The protein-containing fraction was recovered, pooled, and dialyzed in distilled water.

\section{Animal Study Population}

Thirty-five (Albino Wistar rats), 6-8 weeks old, were divided into 5 ( 7 each cage measuring $45 \times 30 \times 42 \mathrm{~cm}$ ), labelled A-E, and placed in large and well circulated enclosures with a proper temperature of $25 \mathrm{oC}$ with relative humidity, to acclimate at the Federal University of Lokoja's animal house unit. Group A was the control group, and groups B-E were the test groups, with 30 percent, 50 percent, 70 percent, and 90 percent administered. Juglar Nigra, Linn Lectin concentration/volume based on body weight A dry grinded walnut was fed to the Wistar rats. The medication was administered intraperitoneally. Each calculated dose was given $5 \mathrm{~mL}$ based on the percentage of concentration ranging from $30-90 \%$ of dilutions.

\section{Weight and Volume of Lectin Administration}

Each group of the animal's body weight was predetermined by using spring balance in order to know the volume/concentration of the Lectin that was administered, the administered dose was determined according to their body weight.

\section{Dose $=\underline{\text { Body weight } X \text { 5ML }}$ 1000}

\section{Lectin Concentration}

Distilled water for Group A (Control)

$30 \%=30 \mathrm{~g}$ of air dried Juglan, nigra, Linn Lectin was dissolved in $100 \mathrm{~mL}$ of water for Group B.

$50 \%=50 \mathrm{~g}$ air dried Juglan, nigra, Linn Lectin was dissolve in $100 \mathrm{~mL}$ of water for Group C.

$70 \%=70 \mathrm{~g}$ of Juglar Nigra, Linn Lenn Lectin was dissolved in $100 \mathrm{~mL}$ of water for Group D.

$90 \%=90 \mathrm{~g}$ was dissolved in $100 \mathrm{~mL}$ of water for Group E

\section{Lectin Administration}

Laboratory animals were allowed to acclimatize in the laboratory house for 10 days. On $14^{\text {th }}$ and $26^{\text {th }}$ days, $1^{\text {st }}$ and $2^{\text {nd }}$ lectin administration were done appropriately in Groups B-E intraperitoneal injection with Juglar nigra Lectin according to their body weight while the control (Group A) were injected with distilled water.

\section{Animal Sample Collection}

The total numbers of 35 and 17 Wistar rats respectively for haematological parameters and LD50 were procured for the research work and the Nigerian walnut (Juglan nigra) that was used were procured from Lokoja. The study were carried out in both Federal University Lokoja and Federal University Lokoja. The Basal level (BL), First harvest (FH) and Second harvest (SH) of blood samples were collected on the $12^{\text {th }}, 24^{\text {th }}$ and $36^{\text {th }}$ days respectively animals from ocular puncture from each animal group and then dispensed $3 \mathrm{~mL}$ in EDTA bottle for hematological parameters.

\section{Sample Analysis}

PCV (Packed Cell Volume), RBC (Red Blood Cell Count), Hb, platelet count, and differential white cell count were all determined using blood samples treated with EDTA. The RBC, WBC, and platelet counts were assessed using a 5-part SYSMEX K2W Haematology auto analyzer, and the differential white blood cell count was determined manually by microscopic staining with Leishman according to Ochei and Kolhatka [10]. All data collected were subject to analysis of (ANOVA) using SPPS. Duncan 1980, multiple ranges test were used to separate significant differences among the result, generated according to the Lectin concentration administered in University of Benin. 
Determination of The Lethal Dose of Juglan nigra, Lectin Sixteen (16) mice weighing between 19 and $32 \mathrm{~g}$ were utilised in the experiments to determine the safety of Juglan, nigra Lectin. For the first day of the trial, mice were divided into three groups: $\mathrm{A}, \mathrm{B}$, and $\mathrm{C}$, and $10 \mathrm{mg} / \mathrm{kg}, 100 \mathrm{mg} / \mathrm{kg}$, and $1000 \mathrm{mg} / \mathrm{kg}$ were administered intraperitoneally into each group. The second day study focused on groups D, E, F, and G, which received injections of $1000 \mathrm{mg} / \mathrm{kg}, 1600 \mathrm{mg} / \mathrm{kg}, 2900 \mathrm{mg} / \mathrm{kg}$, and 5000 $\mathrm{mg} / \mathrm{kg}$, respectively. The animals were observed on a daily basis to determine the number of deaths or non-deaths in each group. Lorke's technique was used to calculate the $\mathrm{LD}_{50}(1983)$.

\section{RESULTS}

In the tables, the means, standard deviation (STD), and P-Values of the Haematological parameters WBC, RBC, HB, Platelet, Neutrophil, Lymphocyte, Monocyte, Basophil, and Eosinophil of the control and test groups are shown. Table 1 displays the mean and standard deviation of the base line analysis at various doses. The table demonstrates that the control group's mean weight, WBC, RBC, HB, PCV, NEU, EOSI, and BASO are considerably $(p<0.05)$ lower than the test group's. While PLT is significantly $(p<0.05)$ greater for controls, LYM is significantly $(p<0.05)$ higher for the different concentrations. Table 2 displays the mean and standard deviation of the 30 percent lectin concentration supplied to the individuals. The chart also demonstrates that the baseline WBC, PVC, MT, L, and Baso are much lower than on other harvest days. While the mean $\mathrm{HB}, \mathrm{N}, \mathrm{M}$ values are statistically significantly higher in the baseline compared to other harvest days.

Table 3 displays the mean and standard deviation of the 50 percent lectin concentration supplied to the individuals. The table demonstrates that the baseline mean weight, WBC, HB, BASO, MT, L, Baso, is much lower than that of previous harvest days. In terms of mean RBC, HB, and PCV, NEU had statistically significant higher mean values in the baseline than other harvest days. Table 4 displays the mean and standard deviation of the 70 percent lectin concentration supplied to the individuals. The table also demonstrates that the baseline WBC, RBC, HB, PCV, LYM, $\mathrm{MONO}$, and BASO levels are much higher than on other harvest days. In terms of mean weight, NEU has statistically lower mean values in the baseline compared to other harvest days.

Table 5 displays the mean and standard deviation of the 90 percent lectin concentration supplied to the individuals. The table also demonstrates that the baseline WBC, HB, NEU, MONO, and BASO are much greater than on other harvest days. When compared to other harvest days, the mean weight, PLT, and LYM indicate statistically significant lower mean values in the baseline. Table 6 displays the mean and standard deviation of the 30 percent lectin concentration supplied to the individuals. The table also demonstrates that the mean WBC, PCV, MT, L, and Baso for the baseline harvest day are significantly lower than those for the other harvest days.

While the mean RBC, HB, NEU, and MONO values are statistically greater in the baseline compared to other harvest days. Table 8 displays the mean and standard deviation of the 70 percent lectin concentration supplied to the individuals. The table also demonstrates that the baseline WBC, RBC, HB, PCV, LYM, $\mathrm{MONO}$, and Eosinophil levels are much higher than on other harvest days. The mean and standard deviation of the 90 percent concentration supplied to the individuals are shown in Table 9.
The table also demonstrates that the baseline HB, PCV, NEU, Monocyte, and Basophil levels are much greater than on other harvest days. While the mean WBC, Platelet, and Lymphocyte counts are significantly lower in the baseline compared to other harvest days. Table 10 demonstrated that Juglan nigra Lectin was a safe extract on experimental animals as it was administered at a very large dose of $1600 \mathrm{mg} / \mathrm{Kg}$ into $25 \mathrm{~g}$ of mice. During the course of the study, no deaths were reported.

Table 1. Result of mean and standard deviation of the base line analysis.

\begin{tabular}{llllllll}
\hline \multicolumn{1}{c}{ Control } & $30 \%$ & $50 \%$ & $70 \%$ & $90 \%$ & F & P \\
\hline WBCx $10^{9}$ & $7.29 \pm 0.19$ & $8.30 \pm 0.20$ & $10.20 \pm 0.13$ & $9.24 \pm 0.21$ & $10.40 \pm 0.15$ & $1370909<0.0001$ \\
RBCx10 12 & $5.66 \pm 0.40$ & $5.75 \pm 0.57$ & $5.83 \pm 0.28$ & $6.02 \pm 0.49$ & $6.20 \pm 0.48$ & 8.002 & $<0.0001$ \\
HBg/dl & $11.52 \pm 0.10$ & $11.60 \pm 0.19$ & $11.61 \pm 0.19$ & $12.42 \pm 0.13$ & $12.37 \pm 0.19$ & 262 & $<0.0001$ \\
PCV\% & $34.50 \pm 0.56$ & $34.70 \pm 0.23$ & $34.70 \pm 0.26$ & $37.10 \pm 0.35$ & $36.80 \pm 0.34$ & 423.8 & $<0.0001$ \\
PLTx10 & $365.00 \pm 9.91$ & $272.00 \pm 8.60$ & $314.10 \pm 3.11$ & $352.00 \pm 24.15$ & $307.30 \pm 4.11$ & 309.3 & $<0.0001$ \\
NEU\% & $41.20 \pm 3.86$ & $64.00 \pm 2.79$ & $52.00 \pm 5.11$ & $35.20 \pm 2.21$ & $54.30 \pm 2.78$ & 365.3 & $<0.0001$ \\
LYM\% & $56.00 \pm 2.65$ & $30.00 \pm 2.34$ & $43.00 \pm 1.07$ & $59.00 \pm 1.30$ & $41.01 \pm 1.41$ & 1411 & $<0.0001$ \\
MONO\% & $2.00 \pm 1.01$ & $1.00 \pm 0.81$ & $0.00 \pm 0.00$ & $4.00 \pm 1.45$ & $2.00 \pm 1.01$ & 80.23 & $<0.0001$ \\
EOSI\% & $2.00 \pm 0.95$ & $5.00 \pm 0.91$ & $5.00 \pm 0.91$ & $2.08 \pm 0.94$ & $3.14 \pm 1.66$ & 62.68 & $<0.0001$ \\
BASO $\%$ & $0.00 \pm 0.00$ & $0.00 \pm 0.00$ & $0.00 \pm 0.00$ & $0.52 \pm 1.69$ & $0.00 \pm 0.00$ & 3.314 & 0.0121
\end{tabular}

KEY: WBC-White Blood Cell, RBC- Red Blood Cell, PLT- Platelets, Hb- Haemoglobin, PCVPacked Cell Volume, Mono-Monocyte, Eos-Eosophil, Lym-Lymphocyte, Baso-Basophil.

Table 2. Result of mean and standard deviation of the $30 \%$ concentration of lectin administered.

\begin{tabular}{lllllc}
\hline $\begin{array}{l}\text { Concen- } \\
\text { tration }\end{array}$ & \multicolumn{1}{c}{ BL } & \multicolumn{1}{c}{ FH } & \multicolumn{1}{c}{ SH } & \multicolumn{1}{c}{ F } & \multicolumn{1}{c}{ p } \\
\hline WBCx10 & $9.68 \pm 0.61$ & $10.5 \pm 0.48$ & $13.0 \pm 0.88$ & 228.1 & $<0.0001$ \\
RBCx10 12 & $6.3 \pm 0.605$ & $6.2 \pm 0.141$ & $7.1 \pm 0.10$ & 64.54 & $<0.0001$ \\
HBg/dl & $12.7 \pm 0.156$ & $12.06 \pm 0.367$ & $13.0 \pm 0.112$ & 714356 & $<0.0001$ \\
PCV\% & $34.5 \pm 0.69$ & $36 \pm 1.0$ & $39.5 \pm 0.87$ & 309.6 & $<0.0001$ \\
PLTx10 & $289.9 \pm 10.445$ & $395 \pm 5.487$ & $403 \pm 2.165$ & 2907 & $<0.0001$ \\
NEU\% & $62.8 \pm 0.927$ & $43 \pm 0.968$ & $38.5 \pm 0.707$ & 7642 & $<0.0001$ \\
LYM\% & $32.13 \pm 1.166$ & $51.13 \pm 0.927$ & $60.2 \pm 0.829$ & 7414 & $<0.0001$ \\
MONO\% & $1.01 \pm 0.708$ & $0.187 \pm 0.105$ & $0.000 \pm 0.000$ & 59.18 & $<0.0001$ \\
EOSI\% & $4.125 \pm 0.927$ & $4.87 \pm 0.649$ & $1.0 \pm 0.751$ & 240 & $<0.0001$ \\
BASO\% & $0.000 \pm 0.000$ & $0.65 \pm 0.13$ & $0.23 \pm 0.14$ & 312.5 & $<0.0001$
\end{tabular}

Table 3. Result of mean and standard deviation of the $50 \%$ concentration of lectin administered.

\begin{tabular}{|c|c|c|c|c|c|}
\hline $\begin{array}{l}\text { Concen- } \\
\text { tration }\end{array}$ & BL & $\mathrm{FH}$ & SH & $\mathrm{F}$ & $\mathrm{p}$ \\
\hline WBCx $10^{9}$ & ${ }^{9} 11.29 \pm 0.31$ & $19.23 \pm 0.17$ & $10.4 \pm 0.54$ & 269 & $<0.0001$ \\
\hline $\mathrm{RBC} \times 10^{12}$ & ${ }^{2} 7.2 \pm 0.14$ & $6.21 \pm 0.22$ & $6.5 \pm 0.17$ & 280.7 & $7<0.0001$ \\
\hline $\mathrm{HBg} / \mathrm{dl}$ & $12.7 \pm 0.17$ & $11.6 \pm 0.21$ & $12.3 \pm 0.13$ & 38126 & $6<0.0001$ \\
\hline PCV\% & $36.8 \pm 1.48$ & $34.1 \pm 0.78$ & $36 \pm 0.71$ & 61.14 & $4<0.0001$ \\
\hline PLTx $10^{9}$ & $350.1 \pm 1.17$ & $7371.8 \pm 41.1$ & $2363.9 \pm 6.17$ & $7 \quad 7.32$ & 0.0011 \\
\hline NEU\% & $56 \pm 1.23$ & $51.3 \pm 1.11$ & $39.13 \pm 1.69$ & 91421 & $<0.0001$ \\
\hline LYM $\%$ & $37.3 \pm 1.09$ & $42.13 \pm 1.17$ & $58 \pm 0.71$ & 4023 & $<0.0001$ \\
\hline MONO $\%$ & $0.15 \pm 0.07$ & $0 \pm 0.00$ & $1.075 \pm 0.51$ & 1134.3 & $3<0.0001$ \\
\hline EOSI \% & $7.05 \pm 1.06$ & $7.08 \pm 0.08$ & $2.15 \pm 0.13$ & 737.2 & $2<0.0001$ \\
\hline BASO $\%$ & $0.47 \pm 0.41$ & $0 \pm 0.00$ & $0.225 \pm 0.16$ & 629.95 & $5<0.0001$ \\
\hline
\end{tabular}

Table 4. Result of mean and standard deviation of the $70 \%$ concentration of lectin administered.

\begin{tabular}{llllcc}
\hline $\begin{array}{l}\text { Concen- } \\
\text { tration }\end{array}$ & \multicolumn{1}{c}{$\mathrm{BL}$} & \multicolumn{1}{c}{$\mathrm{FH}$} & \multicolumn{1}{c}{ SH } & $\mathrm{F}$ & $\mathrm{p}$ \\
\hline $\mathrm{WBCx} 10^{9}$ & $9.20 \pm 0.17$ & $8.50 \pm 0.18$ & $8.49 \pm 0.24$ & 126193 & $<0.0001$ \\
$\mathrm{RBCx} 10^{12}$ & $7.30 \pm 0.07$ & $6.08 \pm 0.08$ & $6.76 \pm 0.09$ & 2023 & $<0.0001$ \\
$\mathrm{HBg} / \mathrm{dl}$ & $13.05 \pm 0.07$ & $12.10 \pm 0.11$ & $12.04 \pm 0.05$ & 1729 & $<0.0001$ \\
$\mathrm{PCV} \%$ & $38.63 \pm 0.99$ & $36.54 \pm 0.32$ & $36.10 \pm 0.07$ & 176.4 & $<0.0001$ \\
$\mathrm{PLTx} 10^{9}$ & $412.60 \pm 2.12$ & $364.00 \pm 2.29$ & $525.63 \pm 4.09$ & 27283 & $<0.0001$ \\
$\mathrm{NEU} \%$ & $30.63 \pm 0.70$ & $55.00 \pm 2.29$ & $64.00 \pm 1.12$ & 4478 & $<0.0001$ \\
$\mathrm{LYM} \%$ & $62.13 \pm 1.05$ & $39.25 \pm 1.20$ & $31.00 \pm 0.71$ & 8964 & $<0.0001$ \\
MONO\% & $1.78 \pm 0.84$ & $1.23 \pm 0.16$ & $0.13 \pm 0.10$ & 99.99 & $<0.0001$ \\
EOSI\% & $6.04 \pm 1.12$ & $7.08 \pm 0.08$ & $5.08 \pm 0.51$ & 69.07 & $<0.0001$ \\
BASO $\%$ & $0.21 \pm 0.16$ & $0.00 \pm 0.00$ & $0.00 \pm 0.00$ & 60.29 & $<0.0001$
\end{tabular}


Table 5. Result of mean and standard deviation of the $90 \%$ lectin administered.

\begin{tabular}{lccccc}
\hline $\begin{array}{l}\text { Concen- } \\
\text { tration }\end{array}$ & BL & FH & SH & F & p \\
\hline WBCx10 $^{9}$ & $10.90 \pm 0.479$ & $10.13 \pm 0.129$ & $10.90 \pm 0.479$ & 43.64 & $<0.0001$ \\
RBCx10 & $6.50 \pm 0.105$ & $6.30 \pm 0.504$ & $6.88 \pm 0.482$ & 18.32 & $<0.0001$ \\
HBg/dl & $13.06 \pm 0.099$ & $12.58 \pm 0.097$ & $12.11 \pm 0.105$ & 783.6 & $<0.0001$ \\
PCV\% & $38.9 \pm 0.757$ & $37.7 \pm 0.318$ & $36.3 \pm 0.316$ & 229.7 & $<0.0001$ \\
PLTx10 & $357.8 \pm 4.763$ & $420.3 \pm 4.465$ & $465.0 \pm 10.689$ & 1941 & $<0.0001$ \\
NEU\% & $52.8 \pm 1.561$ & $50.75 \pm 1.479$ & $49.25 \pm 0.829$ & 62.78 & $<0.0001$ \\
LYM\% & $38.6 \pm 2.497$ & $41.04 \pm 0.505$ & $47.05 \pm 1.129$ & 255.8 & $<0.0001$ \\
MONO\% & $2.04 \pm 1.002$ & $1.175 \pm 0.097$ & $0.775 \pm 0.504$ & 34.64 & $<0.0001$ \\
EOSI\% & $5.10 \pm 0.112$ & $6.087 \pm 0.511$ & $3.013 \pm 1.119$ & 169.5 & $<0.0001$ \\
BASO\% & $1.05 \pm 0.711$ & $1.00 \pm 0.707$ & $0.20 \pm 0.122$ & 23.41 & $<0.0001$
\end{tabular}

Table 6. Result of $30 \%$ concentration after second exposure.

\begin{tabular}{lccccc}
\hline $\begin{array}{l}\text { Haem/ } \\
\text { parameter }\end{array}$ & BL & FH & SH & F & P \\
\hline WBCx10 & $9.68 \pm 0.610$ & $10.5 \pm 0.480$ & $13.0 \pm 0.88$ & $228.1<0.0001$ \\
RBCx10 & $6.30 \pm 0.685$ & $6.2 \pm 0.141$ & $7.1 \pm 0.10$ & $51.19<0.0001$ \\
HBg/dl & $11.7 \pm 0.156$ & $12.06 \pm 0.367$ & $13.0 \pm 0.112$ & $275.7<0.0001$ \\
PCV\% & $34.5 \pm 0.690$ & $36.0 \pm 1.00$ & $39.5 \pm 0.87$ & $309.6<0.0001$ \\
PLTx10 & $289 \pm 0.445$ & $395 \pm 5.487$ & $403 \pm 2.165$ & $12151<0.0001$ \\
NEU\% & $62.8 \pm 0.927$ & $43.0 \pm 0.968$ & $38.5 \pm 0.707$ & $7642<0.0001$ \\
LYM\% & $32.1 \pm 1.166$ & $51.13 \pm 0.927$ & $60.2 \pm 0.829$ & $7431<0.0001$ \\
MONO\% & $1.01 \pm 0.708$ & $0.187 \pm 0.105$ & $0.000 \pm 0.000$ & $59.18<0.0001$ \\
EOSI\% & $4.125 \pm 0.927$ & $4.87 \pm 0.649$ & $1.00 \pm 0.757$ & $238.8<0.0001$ \\
BASO\% & $0.000 \pm 0.000$ & $0.65 \pm 0.130$ & $0.23 \pm 0.14$ & $312.5<0.0001$
\end{tabular}

Table 7. Result of 50\% Concentration after Second Exposure.

\begin{tabular}{lccccc}
\hline $\begin{array}{l}\text { Haem/ } \\
\text { parameter }\end{array}$ & BL & FH & SH & F & P \\
\hline WBCx10 $^{9}$ & $11.29 \pm 0.309$ & $9.23 \pm 0.171$ & $10.4 \pm 0.54$ & 269.2 & $<0.0001$ \\
RBCx10 & $7.2 \pm 0.140$ & $9.23 \pm 0.171$ & $10.4 \pm 0.54$ & 808.6 & $<0.0001$ \\
HBg/dl & $12.7 \pm 0.166$ & $11.6 \pm 0.21$ & $12.3 \pm 0.132$ & 365.4 & $<0.0001$ \\
PCV\% & $36.8 \pm 1.479$ & $34.1 \pm 0.781$ & $36.0 \pm 0.707$ & 61.25 & $<0.0001$ \\
PLTx10 & $350.1 \pm 1.166$ & $371.8 \pm 4.116$ & $363.9 \pm 6.173$ & 224.5 & $<0.0001$ \\
NEU\% & $56.0 \pm 1.225$ & $51.3 \pm 1.111$ & $39.13 \pm 1.691$ & 1423 & $<0.0001$ \\
LYM\% & $37.3 \pm 1.089$ & $42.13 \pm 1.166$ & $58.0 \pm 0.707$ & 4044 & $<0.0001$ \\
MONO\% & $0.15 \pm 0.071$ & $0.000 \pm 0.000$ & $1.075 \pm 0.512$ & 133.2 & $<0.0001$ \\
EOSI\% & $7.05 \pm 1.059$ & $7.08 \pm 0.083$ & $2.150 \pm 0.132$ & 737.9 & $<0.0001$ \\
BASO\% & $0.470 \pm 0.411$ & $0.000 \pm 0.000$ & $0.225 \pm 0.156$ & 30.02 & $<0.0001$
\end{tabular}

Table 8. Result of 70\% Concentration after second Exposure.

\begin{tabular}{lccccc}
\hline $\begin{array}{l}\text { Haem/ } \\
\text { parameters }\end{array}$ & BL & FH & SH & F & P \\
\hline WBCx10 & $9.20 \pm 0.170$ & $8.50 \pm 0.188$ & $8.49 \pm 0.236$ & $145.1<0.0001$ \\
RBCx10 & $7.30 \pm 0.071$ & $6.08 \pm 0.083$ & $6.76 \pm 0.086$ & $2031<0.0001$ \\
HBg/dl & $13.05 \pm 0.071$ & $12.10 \pm 0.112$ & $12.04 \pm 0.048$ & $1695<0.0001$ \\
PCV\% & $38.63 \pm 0.992$ & $36.5 \pm 0.316$ & $36.10 \pm 0.071$ & $178.3<0.0001$ \\
PLTx10 & $412.6 \pm 2.118$ & $364.0 \pm 2.291$ & $525.6 \pm 4.091$ & $27268<0.0001$ \\
NEU\% & $30.63 \pm 0.696$ & $55.0 \pm 2.291$ & $64.0 \pm 1.118$ & $4482<0.0001$ \\
LYM\% & $62.13 \pm 1.052$ & $39.25 \pm 1.198$ & $31.0 \pm 0.707$ & $8979<0.0001$ \\
MONO\% & $1.78 \pm 0.84$ & $1.225 \pm 0.156$ & $0.125 \pm 0.097$ & $100.8<0.0001$ \\
EOSI\% & $6.04 \pm 1.120$ & $4.04 \pm 1.120$ & $5.075 \pm 0.5117$ & $37.91<0.0001$ \\
BASO $\%$ & $0.213 \pm 0.162$ & $0.537 \pm 0.122$ & $0.000 \pm 0.000$ & $186.7<0.0001$
\end{tabular}

Table 9. Result of 90\% Concentration after second Exposure.

\begin{tabular}{lccccc}
\hline $\begin{array}{l}\text { Haem/ } \\
\text { parameter }\end{array}$ & BL & FH & SH & F & p \\
\hline WBCx10 $^{9}$ & $8.61 \pm 0.169$ & $10.13 \pm 0.129$ & $10.90 \pm 0.479$ & $519.1<0.0001$ \\
RBCx10 12 & $6.50 \pm 0.105$ & $6.30 \pm 0.504$ & $6.88 \pm 0.479$ & $18.43<0.0001$ \\
HBg/dl & $13.06 \pm 0.099$ & $12.58 \pm 0.097$ & $12.11 \pm 0.105$ & $783.6<0.0001$ \\
PCV\% & $38.9 \pm 0.757$ & $37.7 \pm 0.318$ & $36.3 \pm 0.316$ & $229.7<0.0001$ \\
PLTx10 & $358 \pm 4.763$ & $420.3 \pm 4.465$ & $465 \pm 10.689$ & $1933<0.0001$ \\
NEU\% & $52.8 \pm 1.561$ & $50.75 \pm 1.479$ & $49.25 \pm 0.829$ & $62.78<0.0001$ \\
LYM\% & $38.6 \pm 2.497$ & $41.04 \pm 0.505$ & $47.06 \pm 1.129$ & $256.4<0.0001$ \\
MONO\% & $2.04 \pm 1.002$ & $1.175 \pm 0.097$ & $0.775 \pm 0.504$ & $34.64<0.0001$ \\
EOSI\% & $5.10 \pm 0.112$ & $6.087 \pm 0.511$ & $3.013 \pm 1.119$ & $169.5<0.0001$ \\
BASO $\%$ & $1.05 \pm 0.711$ & $1.00 \pm 0.707$ & $0.200 \pm 0.122$ & $23.41<0.0001$
\end{tabular}

Table 10. Result of the lethal dose $\left(\mathrm{LD}_{50}\right)$.

\begin{tabular}{ccccccc}
\hline $\begin{array}{c}\text { Table } \\
\text { Distributio }\end{array}$ & $\begin{array}{c}\text { Dose } \\
\mathrm{mg} / \mathrm{Kg}\end{array}$ & $\begin{array}{c}\text { Animal } \\
\text { Mark }\end{array}$ & $\begin{array}{c}\text { Weight of } \\
\text { Animal }\end{array}$ & $\begin{array}{c}\mathrm{mg} \text { Admi- } \\
\text { nister }\end{array}$ & $\begin{array}{c}\text { No Of } \\
\text { Death }\end{array}$ & $\begin{array}{c}\text { Volume } \\
\mathrm{mg} / \mathrm{mL}\end{array}$ \\
\hline A & 10 & Head & 21 & 0.21 & nil & 0.21 \\
& & TaIL & 20 & 0.2 & nil & 0.2 \\
& & Trunk & 18 & 0.18 & nil & 0.18 \\
B & \multirow{2}{*}{100} & Head & 22 & 2.2 & nil & 0.22 \\
& & Tail/Trunk & 20 & 20 & nil & 0.2 \\
& & R.Hind & 19 & 1.9 & nil & 0.19 \\
C & \multirow{2}{*}{1000} & L.Hind & 21 & 21 & nil & 0.21 \\
& & R.Ear & 18 & 18 & nil & 0.18 \\
& & L.Ear & 20 & 20 & nil & 0.2 \\
D & \multirow{2}{*}{1200} & Head & 27 & 27 & nil & 0.27 \\
& & Trunk & 24 & 24 & nil & 0.24 \\
E & \multirow{2}{*}{1600} & Tail & 32 & $512(51.20)$ & nil & 0.28 \\
& & R.Hind & 25 & 40 & nil & 0.2 \\
F & \multirow{2}{*}{2900} & L.Hind & 26 & 75.4 & nil & 0.37 \\
& & R.Ear & 30 & 87 & nil & 0.44 \\
G & \multirow{2}{*}{5000} & L. Ear & 25 & 125 & nil & 0.25 \\
& & Unmarked & 23 & 115 & nil & 0.23
\end{tabular}

\section{DISCUSSION}

Due to the high concentration of Juglan nigra in the rat, the lectin provided to them increased the number of monocytes by 0.0116 $(\mathrm{P}<0.05)$. This corroborates the findings of Ojobor et al., [3]. The white blood cell count was considerably enhanced following injection of a high concentration of Juglan nigra, Lectin into an animal at a volume of 10.69 for baseline, but rose to 12.30 following injection of a $30 \%$ concentration of second harvest at a volume of $0.0479(\mathrm{P}<0.05)$. While this study employed Nigerian walnut as the source of lectin, the rise in these blood cells is consistent with the findings of Ezzat et al [11] who used Moringa lectin and Apeh et al [12] who used walnut lectin.

When the very first and second harvests were matched to the baseline data, the test animal demonstrated significant differences in haematological parameters. While compared to the baseline result, the WBC, Neutrophils, Lymphocytes, Monocytes, and Basophil revealed no significant difference in the results for the first and second harvests. This contradicts Udedi et al[13].'s finding that the rats' haematological parameters showed a substantial decrease in white blood cells (WBCs) and lymphocytes when compared to the control group of mice used in the experiment. Additionally, the study contradicts Oguwike et al[14] .'s assertion that "walnut meal had no influence on haemoglobin concentration, white blood cell count, packed cell volume, or platelet counts."

When the RBC, HB, and PCV values were compared to the baseline values, a significant increase in value of 0.02215 $(\mathrm{P}<0.05)$ was observed. This indicates that the lectinic content of Juglan nigra is capable of identifying haematopoietic cell lines, which is consistent with the work of Gorakshakar et al. [7] that lectins improve haematopiesis. This is also consistent with the findings of Ogundolie et al. [15], who observed a rise in packed cell volume (PCV), red blood cells (RBC), haemoglobin (HGB), and platelets (PLT) following lectin administration to Swiss mice infected with P.berghei (NK65). This is also consistent with the findings of Adeyemo and Longe [16], who found haematologic activity in broilers. This study also partially corroborated Adejola et al. [17], who reported an increase in HB, RBC, platelet, HET (Heterophils), and MON (Monocytes) $(\mathrm{p}<0.05)$. 
The increase might be explained by Habibpour et al [18] hypothesis that hydro alcoholic Walnut leaf extract protects RBC and haemoglobin from oxidative stress. When compared to the baseline result, the platelet count was significantly increased by $0.0026(\mathrm{P}<0.05)$ when compared to the first and second harvests, indicating that Juglan nigra lectin can induce platelets in rats but does not enhance or promote the coagulation test procedure in serum samples from rats. Similarly, this verified Kirichuk and Voskoboi's [19] observation that some plant lectins bind to distinct carbohydrate-determinant glycoproteins. At different phases of concentration and delivery of Juglan nigra, the eosinophil count increased significantly in comparison to monocytes, reaching a value of 0.0162 . $(\mathrm{P}<0.05)$ This might be due to an allergic response during the lectin delivery time or because the lectin increases eosinophil formation. Because the Juglan nigra, Lectin extract was used at a very high concentration of $1600 \mathrm{mg} / \mathrm{kg}$ in $25 \mathrm{~g}$ of mice, it was a safe extract to utilise on the experimental animals.

There were no deaths registered over the study's duration. This investigation confirms Etim et al [20] concluded that Juglan nigra is non-toxic ( $\mathrm{LD}_{50}>700 \mathrm{mg} / \mathrm{kg}$ body weight). Daniel et al. [21] established the non-toxic nature of walnut lectin by demonstrating that it was undetectable in rats' haematological measures. Baseline outcome in relation to varied administration concentrations of $30 \%, 50 \%, 70 \%$, and $90 \%$. This is for the baseline sample analysis prior to lectin injection. The baseline values were low in comparison to the values obtained after lectin injection, notably for eosinophils, but other blood cell counts increased considerably following lectin treatment. As a result, lectin acts as an inducer of hematopoietic cell line formation.

\section{CONCLUSION}

is not harmful to Swiss Wistar rats or humans. The study discovered that using Nigerian walnut (Juglan nigra) stimulates the haemopoietic system and Eosinophil activity. As a result, it may be advised for those who are immunocompromised, have bone marrow loss, or are prone to parasite infection. The lectin Juglan nigra is a processed plant lectin with a high iron concentration regardless of the degree of processing. It is safe for human ingestion due to its beneficial effect on several haematological parameters and is non-toxic to the human body. Thus, lectin from Nigerian walnut is a more effective supply of iron and other physiochemicals required for improved haemopoiesis. This study proposes that haematinic drug manufacturers and pharmacies conduct more research into the utilisation of Nigerian walnut Juglan nigra as a component of blood production medicine formulations. It may be a defining moment in the management and treatment of anaemic individuals.

\section{ACKNOWLEDGMENTS}

Medical Laboratory Scientists who provided technical assistance and Department of Haematology, College of Basic Medicine of University of Benin where the work was presented.

\section{CONFLICT OF INTEREST}

None

\section{FINANCIAL SUPPORT}

None

ETHICS STATEMENT: Ethical Approval was gotten from Federal Medical Centre, Lokoja.

\section{REFERENCES}

1. Şen SM. and Karadeniz T. The Nutritional Value of Walnut. J. Hyg Eng Des, 2015:68-71.

2. Akpuaka MU, Nwankwo E. Extraction, analysis and utilization of a drying oil from Tetracarpidium conophorum. Biores Technol, 2000;73:195-196.

3. Ojobor CC, Anosike CA, Ani CC. Studies on the phytochemical and nutritional properties of Tetracarpidium conophorum (Black walnut) seeds. J Glob Biosci, 2015;4(2):1366-1370.

4. Ghizlane K, Said B, Mohammed E, Abdelmajid H. Biochemical characterization and antioxidant activity of walnut kernel (Juglans regia L.) of accessions from Middle and High Atlas in Morocco Acta Scientiarum. Biol Sci, 2019:41.

5. Rebollo A, Schmitt C. Ikaros, Aiolos and helios: Transcription Regulator and Lymphoid Malignancies. J Immunol Cell Biol, 2003;81(3):171-175.

6. Krispin S. Plant Haemagglutinin; British Medical Journal. 2000;318:1023-1026.

7. Gorakshakar AC, Ghosh K. Use of lectins in immunohematology. Asian J Transfus Sci 2016;10:12-21.

8. Meshkini A, Tahmasbi M, Anti-platelet aggregation activity of walnut hull extract via suppression of ROS generation and caspase activation, J Acupunct Meridian Stud. 2017;10(3):193-203.

9. Vijaya M, Reddy B, Banik NL and P. Sasikala P. Extraction and purification of lectin from plant seeds an empirical study on Artocarpus sp. Int. J. Res. Ayurveda Pharm. 2016;7(2):236-240

10. Ochei J, Kolhatkar J. Medical Laboratory Science Theory \& Practice, 3rd Reprint. 2007:

11. Ezzat SM, El-Gamal RMA, Abd El-Naby AS, Abd El-Hamid SAA Alaa R. A. Mousa ARA. The role of lectin in improving growth performance, feed utilization, immunity, and disease resistance of the Nile tilapia, Oreochromis niloticus fingerlings. Egyptian J Aqua Biol Fish, 2019;23(4):285-300.

12. Apeh VO, Agu CV, Ogugua VN, Uzoegwu PN, Anaduaka EG, Rex TE. Effect of cooking on proximate, phytochemical constituents and hematological parameters of Tetracarpidium conophorum in male albino rats. Eur J Med Plant, 2014;4(12):1388-1399.

13. Udedi SC, Ani ON, Anajekwu BN, Ononamadu CJ, Igwilo IO, Ibeabuchi CG. Ifemeje JC, Lukong $\mathrm{CB}$, Ogbuozobe $\mathrm{GO}$ Nutritional composition and antioxidant activity of African walnut, (Tetracarpidium conophorum). J App Biochem, 2014:107:170-180.

14. Oguwike FN, Ebede S, Offor CC. Evaluation of efficacy of walnut (Juglans nigra) On blood pressure, haematological and biochemical profile of hypertensive subjects. IOSR J Dent Med Sci, 2014;13(10):75-79.

15. Ogundolie OO, Dada EO, Osho IB, Oloruntola DA. Effects of raw ethanolic seed extract of Tetracarpidium conophorum on haematological and histopathological parameters in Swiss albino mice infected with Plasmodium Berghei. J Appl Life Sci Int, 2017:12(2):1-14.

16. Adeyemo GO, Longe OG. Effect of Graded Level of Cottonseed cake on Performance, Haematological and Carcass characteristics of Broilers fed from Day old to 8 weeks of age. Afr J Biochem 2007:6(8):1064 - 1071.

17. Adejola YA, Tiamiyu OD, Bamibe TI, Ayoola AA, Apiakason E. Effects of African Walnut (Tetracarpidium conophorum) Leaf and its Extract on Blood Profiles of Broiler Chickens. Res J Med Plant, 2019:13;74-80. Habibpour S, Mokhtari M., Sharifi E. Effect of hydroalcoholic walnut (Juglans regia) leaf extract on hematological parameters in rat with hypothyroidism. J Anim Biol, 2014:6(3):13-23. Kirichuk VF, Voskoboi IV. Effect of Certain Lectins on Platelet Aggregation in Healthy People. J Tistologiia. 2000:42(11);1094 - 1096.

18. Etim B, Ani C, Uzoma I, Uzoigwe J, Chinemerem N, Adeyemo M, Nwaeme O, and Nwachukwu D. (), Ameliorative Effect of Aqueous Extract of Tetracarpidium Conophorum (African Walnut on Salt Induced Hypertensive Wistar Rats.” Am J Hyper Res, 2018;5(1):17. doi: 10.12691/ajhr-5-1-1

19. Daniel E, Ikipi B, Clement ON. Effect of Ethanolic of Denneettia Tripetala Fruit on Haematological parameters in Albino Wistar Rats. Nig J Physiol Sci, 2008:23(1): 13-17. 